\section{Scientific Growth and Identity Development during a Postbaccalaureate Program: Results from a Multisite Qualitative Study}

\author{
Robin Remich, ${ }^{\dagger}$ Michelle E. Naffziger-Hirsch, ${ }^{\ddagger}$ J. Lynn Gazley, ${ }^{\S}$ \\ and Richard McGee ${ }^{t \| *}$ \\ 'Department of Faculty Affairs and IDepartment of Medical Education, Feinberg School of \\ Medicine, Northwestern University, Chicago, IL 60611; 'Department of Behavioral and Social \\ Sciences, Oakton Community College, Des Plaines, IL 60016; \$ Department of Sociology $\&$ \\ Anthropology, College of New Jersey, Ewing, NJ 08628
}

\begin{abstract}
This report builds upon our previous study, which described five patterns of why college graduates join National Institutes of Health (NIH)-funded diversity-focused Postbaccalaureate Research Education Programs (PREP). A 2015 report from the NIH showed that a high fraction of PREP participants matriculate into PhD and MD/PhD programs. This current study reveals how participants change during PREP, the program elements that facilitate change, and how identity as a graduate student and future scientist develops. Data come from in-depth interviews done at the beginning and end of PREP with 48 individuals from seven PREP programs. Results reveal three domains of development: academics, research, and presentation of oneself; each domain contains a developmental continuum. Key attributes of PREP enabling development include opportunities to attend graduate-level classes and seminars; time to practice reading literature; extended lab time with one's own project; high and explicit expectations from mentors; and multiple opportunities to talk about science and improve communication skills. PREP enabled participants to develop their identities as graduate students and to anticipate being seen by others as highly prepared for PhD training. After PREP, 85\% ( $n=41)$ started the PhD or MD/PhD, making PREP an intervention approach with great potential to broaden participation in biomedical PhD programs.
\end{abstract}

\section{INTRODUCTION}

It is well established that African Americans, Hispanics, and Native Americans are highly underrepresented in science and engineering fields. While these groups make up more than $30 \%$ of the U.S. population, African-American and Hispanic students receive $\sim 16 \%$ of bachelor degrees in biological sciences; they represent $\sim 11 \%$ of graduate students in these fields and $\sim 7 \%$ of those who receive PhDs (National Science Foundation/National Center for Science and Engineering Statistics [NSF/NCES], 2013). Though the underrepresented minority (URM) share of science and engineering bachelor's and master's degrees has been rising since 1993, the URM share of doctorates in these fields has stayed at $\sim 7 \%$ for the past $10 \mathrm{yr}$ (NSF/NCES, 2015). Beyond educational attainment, the representation of scientists from URM backgrounds continues to decline after the $\mathrm{PhD}$, with a notable decline among $\mathrm{PhD}$ students in their intention to enter a research-intensive academic faculty position (National Institutes of Health [NIH], 2012).

Up until 2001, most of the government-funded interventions to broaden participation in science, technology, engineering, and mathematics (STEM) from URM groups targeted students in degree programs, and there was not a systematic way for students to continue to develop as scientists beyond the bachelor's degree if they did not go directly to graduate school. Structuring science support programs to align with
Kenneth Gibbs, Monitoring Editor

Submitted January 15, 2016; Revised March 30, 2016; Accepted April 20, 2016

CBE Life Sci Educ September 1, 2016 15:ar25

DOI: $10.1187 /$ cbe.16-01-0035

*Address correspondence to: Richard McGee ( $r$-mcgeeanorthwestern.edu).

(c) 2016 R. Remich et al. CBE-Life Sciences Education ๑ 2016 The American Society for Cell Biology. This article is distributed by The American Society for Cell Biology under license from the author(s). It is available to the public under an Attribution-Noncommercial-Share Alike 3.0 Unported Creative Commons License (http://creativecommons.org/licenses/ by-nc-sa/3.0).

"ASCB®" and "The American Society for Cell Biology $\circledR^{\prime \prime}$ are registered trademarks of The American Society for Cell Biology. 
educational stages presumes an approach to talent development that progresses linearly through academic milestones with no interruptions. Although exact data are not available, it is not uncommon for college graduates interested in the $\mathrm{PhD}$ to do a few years of research before applying to graduate school to decide whether the $\mathrm{PhD}$ is what they want, refine scientific interests, and/or gain research experience. This period of time may be especially important for students who start from lower-resourced communities or backgrounds. These students may take longer to develop an interest in pursuing academic or science research careers due to factors such as lack of role models, limited access to "real" research opportunities, and lack of guidance about graduate school preparation and admissions (Villerejo et al., 2008; Ovink and Veazey, 2011).

In 2001, the National Institute of General Medical Sciences established the Postbaccalaureate Research Education Program (PREP). PREP was unique, because participants are not enrolled in degree programs. The PREP initiative targets college graduates from URM backgrounds with a strong interest in starting a biomedical $\mathrm{PhD}$ or $\mathrm{MD} / \mathrm{PhD}$ program who did not matriculate into a graduate program after college. PREP grants are awarded to research-intensive institutions to provide mentored research experiences and professional development to facilitate application to high-caliber $\mathrm{PhD}$ programs and completion of rigorous $\mathrm{PhD}$ training (NIH, 2014). Participants are referred to as "PREP Scholars" and receive a salary and benefits with the expectation that they will devote $75 \%$ of their time to mentored research. The remaining time is available for professional development activities, which may include one graduate-level class per term; journal clubs; graduate school preparation and application workshops; communication skills practice; and scientific conferences. Scholars work alongside graduate students and postdoctoral fellows and frequently attend research seminars and other scientific events. Thus, PREP provides a developmental opportunity for a population that did not go directly to graduate school and has great potential but is particularly at risk of not continuing in science research.

The percentage of Scholars who matriculate into $\mathrm{PhD}$ training programs is one metric for evaluating the success of PREP; the current expectation for PREP funding is that $75 \%$ of each PREP cohort matriculates into the $\mathrm{PhD}$ or $\mathrm{MD} / \mathrm{PhD}$, and that $75 \%$ of them will complete their degrees (NIH, 2014). In a 2015 report, Hall and colleagues analyzed the educational and career outcomes of PREP using data from 41 institutions between 2001 and 2014 (Hall et al., 2015). They report positive outcomes, though some outcomes fall just short of the NIH benchmarks for PREP: 1) 65\% of PREP Scholars entered PhD programs; 2) of those who start the $\mathrm{PhD}, \sim 63 \%$ complete it; 3) about half of $\mathrm{PhD}$ graduates were in postdoctoral training at the time of the report, but for those who have completed training, at least $79 \%$ were doing research or engaged in science-related nonresearch work. The authors conclude that $\mathrm{PhD}$ matriculation and completion rates for PREP are strong and are in many cases higher than similar national STEM PhD statistics for URM individuals. However, the Hall et al. (2015) study does not have the ability to reveal why the success rate is high, which students benefit from PREP, and the mechanisms by which PREP is effective. The current study begins to fill this gap.

We have previously reported on 52 PREP Scholars from seven PREP institutions interviewed as they started PREP to understand why they chose PREP rather than beginning graduate school (Gazley et al., 2014). In that analysis, we developed a theoretical framework that integrated identity formation and cultural capital and used that to understand what incoming PREP Scholars felt was missing or what they needed from PREP. Our theoretical orientation with respect to identity development aligns with those who have studied identity as a fluid and changing process of development. Like Holland and colleagues, we view identities as "lived in and through activity [that] must be conceptualized as they develop in social practice" (Holland et al., 1998, p. 5). In addition, we understand identity formation as a process that relies on opportunities to develop cultural capital (Ovink and Veazey, 2011). Identity development involves drawing upon resources in the environment (Carlone and Johnson, 2007) that can be considered cultural capital (Bourdieu, 1984, 1986; Bourdieu and Passeron, 1977) because these resources can be used (spent) to gain access to more resources and opportunities. We use internal identity to refer to how individuals see themselves and their competencies. An external identity, defined as an identity that can be recognized and accessed by others (Carlone, 2004; Malone and Barabino, 2009), can enhance one's internal identity. In some cases, stereotypes (Steele and Aronson, 1995; Steele, 1997) and conflicts between multiple identities can affect identity development, which we found was particularly salient for the American-born black men as they entered PREP. For this paper, we have investigated how participants used the resources in PREP to develop an identity in which they see themselves (internal) and feel ready to be seen by others (external) as capable graduate students.

The results from our first analysis with 52 PREP Scholars, using the framework of identity and cultural capital, showed five patterns of differences in what beginning PREP Scholars expected from PREP, which we have previously described in depth (see Gazley et al., 2014). To set the context for this second report on our longitudinal study of PREP Scholars, we provide brief descriptors and use the pattern names from the first analysis. In three of the patterns, the Scholars came to PREP having done undergraduate research, so all had an idea that they could imagine continuing in research in the future. The largest pattern was the Credential Seekers $(n=25 ; 48 \%)$. They joined PREP with a focus on developing what graduate schools would look for from applicants (external), and they expected to improve a specific area or areas in their graduate school portfolio, such as gaining more research experience, improving grades, or performing better on the Graduate Record Exam. We noted that many of the Credential Seekers envisioned themselves in graduate school because they loved doing research and viewed PREP as a way to continue doing benchwork. In contrast, the next largest pattern, the Path Builders $(n=15$; 29\%), started PREP unsure about graduate school and sought to become more comfortable with pursuing the $\mathrm{PhD}$ or MD/ $\mathrm{PhD}$. They approached PREP to develop an internal sense that going to graduate school was right for them. The PI Aspirants ( $n=4 ; 8 \%$ ) had a longer-term vision that included graduate school and becoming a principal investigator (PI) in an academic setting. Their internal sense of becoming a scientist aligned with their vision of pursuing their own research ideas, and they wanted to develop into highly competitive applicants who would be recognized as such by prestigious graduate 
programs. The PI Aspirants had undergraduate research experiences at strong institutions, and this was the only group in which individuals showed a high consciousness of race playing a role in their past and future. The three black male PI Aspirants had experienced discrimination, had felt conspicuous and/or isolated as the only black men in predominantly white educational settings, and lived with idea that they had to always be the best, which shaped their thinking about educational and career goals.

Scholars in the other two patterns came to PREP with little to no research experiences in science. Discipline Changers $(n=$ 5; 10\%) entered PREP with undergraduate majors in social science and applied science. They had a strong sense of themselves as competent students, and their goal was to redeploy their academic and research skills to biomedical research fields, which were new to them. Similar to the PI Aspirants, they envisioned pursuing careers in an academic environment to work on their developing research interests and questions. Interest Testers, $(n=3 ; 6 \%)$ in contrast to the other four groups, entered PREP with no previous research experience but had majored in science. They joined PREP as a "second chance" and were hopeful of finding a fit with a career direction that included research.

The population for this report includes 48 of the 52 Scholars from the first study who were interviewed at the end of their participation in PREP. The report focuses on how these individuals experienced PREP and describes ways they changed during the program. From qualitative analysis of individual interviews, we report how PREP enabled participants to develop rapidly during the program. By studying a crucial decision pointdeciding whether to go to graduate school—our findings reveal how prospective graduate students think about their own readiness to take this step (internal) and how others will view them as qualified graduate students (external). Our results show how PREP Scholars used resources in the program; how PREP provided a fruitful context for identity development; and the specific mechanisms of PREP that facilitated this development.

In addition, we describe outcomes after PREP and relate these to the five patterns from our first study. Of the 48 Scholars, $41(85 \%)$ began a $\mathrm{PhD}(n=38 ; 79 \%)$ or $\mathrm{MD} / \mathrm{PhD}(n=3$; $6 \%$ right after PREP or within 2 yr of finishing PREP, which is somewhat higher than the outcomes reported by Hall and colleagues in 2015. Because this is our second report of a longitudinal study, we were able to examine whether certain kinds of students, that is, those with different incoming expectations, benefited more from PREP.

\section{METHODS}

The PREP Scholars in this report are part of our larger study, the National Longitudinal Study of Young Life Scientists (NLSYLS). This large, NIH-supported study enrolled a diverse population of 533 undergraduate students, postbaccalaureate participants, and beginning $\mathrm{PhD}$ students from 2008-2011, yielding a sample of 269 biomedical $\mathrm{PhD}$ students. The study uses annual in-depth interviews and currently follows more than 200 students as they move through the $\mathrm{PhD}$ and into early career stages. The goals of the NLSYLS are to understand the complexity of career decision making, what leads to success in contemporary biomedical sciences, and how experiences compare between aspiring scientists from well-represented and URM groups. The study was approved by the institutional
TABLE 1. Race, ethnicity, and gender as reported by study participants

\begin{tabular}{lccc}
\hline Race/ethnicity & $\begin{array}{c}\text { Women } \\
(\mathbf{3 1 ; 6 5 \% )}\end{array}$ & $\begin{array}{c}\text { Men } \\
(\mathbf{1 7} ; \mathbf{3 5 \% )}\end{array}$ & $\begin{array}{c}\text { Total } \\
\text { (percent) }\end{array}$ \\
\hline Black or African American & 16 & 9 & $25(52)$ \\
$\begin{array}{l}\text { Hispanic/Latina(o) } \\
\text { Native American/Alaska }\end{array}$ & 13 & 7 & $20(42)$ \\
$\quad$ Native & 1 & 3 & $4(8)$ \\
$\begin{array}{l}\text { Asian } \\
\text { White/non-Hispanic }\end{array}$ & 2 & 0 & $2(4)$ \\
\hline
\end{tabular}

apercentages are out of 48 and total more than 100 because five identified more than one race and/or ethnicity.

review board (IRB) of Northwestern University Feinberg School of Medicine as project STU0017678. We included 52 beginning PREP Scholars as a subgroup in the NLSYLS; they were first interviewed in 2008 or 2009 as they began PREP at one of seven locations across the United States. For this paper, we draw on interviews at the beginning and end of PREP with the 48 individuals who continued in our study with two or more interviews. Typically, PREP is a 1-yr program, but it can extend to 2 or 3 yr for some participants. Of the 48 Scholars, 38 were in PREP for $1 \mathrm{yr}$, seven for $2 \mathrm{yr}$, and three for $3 \mathrm{yr}$.

The PREP Scholars self-reported their race, ethnicity, and gender (Table 1) on demographic questionnaires before their first interviews. Ninety-four percent $(n=45)$ identified a race and/or ethnicity underrepresented in the sciences: 52\% $(n=$ 25) as black or African American (going forward we use "black" for those who self-identified as black or African American), $42 \%(n=20)$ as Latino/a, $8 \%(n=4)$ as Native American (total is more than 45 , because four identified more than one race/ ethnicity). About $65 \%(n=31)$ are female. All are U.S. citizens or permanent residents.

Interviewers met one-on-one with participants at their PREP institutions for first and second interviews at the start and end of the first PREP year, though 10 second interviews were done by phone due to scheduling conflicts. Those who continued in the study beyond two interviews were interviewed annually by phone. Interview questions were provided via email a few days in advance to encourage reflective responses. Two of the authors (R.R., R.M.) conducted a majority of interviews, with another researcher from the NLSYLS team doing three interviews. The interviewers have extensive experiences advising students in diverse educational settings, and the project PI (R.M.) sensitized the researchers to the design and goals of PREP, because he had developed an initial prototype design that led to PREP. The interview protocols included similar topics at each interview that covered career aspirations; research mentors and role models; and Scholars' perceptions of the influence of gender, race, and ethnicity on their educational experiences. For the end-of-PREP interview, questions were added to explore development and change during PREP, perceptions of the impact of PREP, and plans after PREP. Specifically to probe identity development, we included the following questions: Do you see yourself as a scientist? Are there things in your life that have or could pull you away from being a scientist? (See Supplemental Materials for complete interview protocols.) The audio-recorded interviews averaged about an hour in length and were transcribed and checked for accuracy against the audio recording. 
The first author (R.R.) coded the transcripts using a coding structure with broad themes developed by the NLSYLS team using NVivo qualitative data analysis software (QSR International, 2010). She then developed more specific codes for emerging themes regarding experiences in PREP, the graduate school decision process, impressions of change during PREP, and sources of impact. As coding continued for each transcript using these additional codes, R.R. created and shared theoretical and coding memos with her coauthors. Together they reviewed coding reports, compared themes with first interviews, and came to consensus on the results. Throughout coding and data analysis, the researchers used the theoretical framework and findings developed during the analysis of the first interviews (Gazley et al., 2014) for the present analysis. When presenting data, we use quotations from the transcripts and pseudonyms to refer to participants.

\section{RESULTS}

\section{Change and Development during PREP}

The analysis revealed three discernible domains of change during PREP. Within each domain, individuals developed along a continuum, with some individuals describing dramatic change and some smaller amounts. These domains illuminate change during PREP, which in turn facilitated decisions to start the $\mathrm{PhD}$ or $\mathrm{MD} / \mathrm{PhD}$. The three domains are readiness for academics, readiness for research, and readiness to present oneself. Though readiness for academics and readiness for research do not represent a perfect dichotomy, Scholars talked about these two items separately. For example, Nathan, a black man, named these "the academic and research sides," and Courtney, a Latina, commented, "there's classes; there's lab stuff." Readiness to present oneself highlights the role that speaking and writing about science played in the graduate school decision.
By learning and practicing science communication, Scholars became comfortable seeing themselves as graduate students (internal identity) and confident about presenting their potential to others (anticipating external recognition by others).

Descriptions of the three levels for each domain are summarized in Table 2. (The numbers and percentages in parentheses indicate how many Scholars described changes in each domain through their comments. These numbers represent minimum frequencies of occurrence within the study population, as they emerged spontaneously, not in response to specific questions designed to elicit them. Thus, more Scholars may have achieved each level, but it was just not revealed during the interviews.) The first level is characterized as acquiring something, such as a skill or knowledge. The next level reveals a change in understanding, in which the knowledge or skill is used for application and interpretation. The third level involves becoming, as one sees him/herself aligning with the qualities of a graduate student and, for some, a successful scientist. The timing of PREP between undergraduate and graduate school allowed Scholars to compare their development during PREP with their undergraduate experiences in anticipation of becoming graduate students. Because of different background experiences in college and with undergraduate research, Scholars started PREP at different levels of development. They moved through the levels of each domain based on choices about how to use their time and energy during PREP. The domain levels represent a range and the possibilities of development. Our data showed that not all Scholars moved through all levels evenly or sequentially, but ideally, they moved closer to feeling ready to apply to and successfully matriculate in graduate programs.

Readiness for Academics. PREP Scholars described changes in the "academic side" of readiness for graduate school that

TABLE 2. Domains of change during PREP

\begin{tabular}{|c|c|c|c|c|c|}
\hline & \multicolumn{3}{|c|}{ Three Domains of Change during PREP } & \multirow{2}{*}{\multicolumn{2}{|c|}{ Mechanisms of Change }} \\
\hline & Acquiring & Understanding & Becoming & & \\
\hline $\begin{array}{r}\text { Readiness for } \\
\text { academics }\end{array}$ & $\begin{array}{l}\text { Knowledge } \\
n=28 / 58 \%\end{array}$ & $\begin{array}{c}\longrightarrow \text { How to apply } \\
\text { knowledge } \\
n=26 / 54 \%\end{array}$ & $\begin{array}{l}\rightarrow \text { Able to critique and } \\
\text { evaluate existing } \\
\text { knowledge } \\
n=12 / 25 \%\end{array}$ & ० & $\begin{array}{l}\text { Attending grad-level classes to understand } \\
\text { expectations and teaching style } \\
\text { Attending seminars to gain broader } \\
\text { knowledge } \\
\text { Time for reading literature with repeated } \\
\text { practice and feedback }\end{array}$ \\
\hline $\begin{array}{c}\text { Readiness for } \\
\text { research }\end{array}$ & $\begin{array}{l}\text { Technical skills } \\
n=38 / 80 \%\end{array}$ & $\begin{array}{l}\text { How experiments are } \\
\text { designed and how to } \\
\text { interpret results } \\
n=37 / 77 \%\end{array}$ & $\begin{aligned} & \text { An independent } \\
& \text { researcher with a } \\
& \text { mind-set for the } \\
& \text { researcher lifestyle } \\
n= & 32 / 67 \%\end{aligned}$ & ० & $\begin{array}{l}\text { Extended time in lab with one's own } \\
\text { project } \\
\text { High expectations for mentee indepen- } \\
\text { dence and critical thinking } \\
\text { Explicit PI descriptions for graduate } \\
\text { student researchers }\end{array}$ \\
\hline $\begin{array}{l}\text { Readiness to } \\
\text { present oneself }\end{array}$ & $\begin{array}{l}\text { Speaking and } \\
\text { writing skills } \\
n=32 / 67 \%\end{array}$ & $\begin{array}{l}\text { How communicating } \\
\text { about science } \\
\text { influences one's } \\
\text { thinking about one's } \\
\text { science } \\
n=25 / 52 \%\end{array}$ & $\begin{array}{l}\text { Comfortable seeing } \\
\text { oneself as a graduate } \\
\text { student/scientist and } \\
\text { presenting this identity } \\
\text { to others } \\
n=28 / 58 \%\end{array}$ & ○ & $\begin{array}{l}\text { Multiple guided opportunities to gain, } \\
\text { practice, and improve oral and written } \\
\text { communication skills } \\
\text { Formal, e.g., workshops with instruction } \\
\text { on grant writing, personal statements, and } \\
\text { interviewing; presenting at conferences, } \\
\text { PREP, and lab meetings; leading journal } \\
\text { club; working on manuscripts } \\
\text { Informal, e.g., interacting with grad } \\
\text { students, mentors, faculty, and peers on } \\
\text { campus; networking at conferences }\end{array}$ \\
\hline
\end{tabular}


stemmed from taking classes and experiences, such as participating in journal clubs, studying with classmates, and attending talks. Changes included building confidence with graduate course work, honing study skills and habits, and adding background knowledge. The data revealed growing awareness of the differences between learning as an undergraduate and as a graduate student.

At the first level of academic readiness, confidence increased through acquiring knowledge $(n=28 ; 58 \%)$. Hirsi, a black man, said that, through graduate classes and seminars, he has "a better knowledge base" and can "extract information better," making him "better prepared than if I would have tried to go [to graduate school] right outside of college." For Brandy, PREP offered the opportunity to prove her competence to succeed in graduate-level classes:

"I tested myself by taking a class in the Fall semester, and I definitely proved to myself that I can do it. I got a good grade in the class, and I was very happy for that because it proved to me that I can handle grad school work, and I know grad school is a lot different from undergrad, so although I'm nervous about it, I'm prepared for it." (Brandy, black woman)

Gaining knowledge, especially when verified by earning a "good" grade, was particularly important for those who joined PREP with concerns about their undergraduate grade point averages (GPAs), limited undergraduate curricula, and/or the desire to move into a new academic discipline.

At the next level of the academic domain, more than half of the Scholars ( $n=26 ; 54 \%$ ) developed new ways of learning, specifically moving beyond memorization to practice application and interpretation of knowledge, which many had not experienced or realized as undergraduates. Marie, a Latina, said, "There's a lot more to learning than I thought there was." Reflecting on watching graduate students in classes, she added, "It didn't really hit me until I took these courses [that] you have to discuss papers ... [and show] what you know." Courtney, a Latina, concluded, "[You] don't memorize everything ... [but you] interpret the material and use what you have in books to apply to papers."

A few participants $(n=12 ; 25 \%)$ articulated thinking skills more aligned with becoming researchers and scientists. At this level, they were becoming knowledge producers, not just receiving or using knowledge. Crystal showed this shift as she talked about not just accepting others' explanations but becoming someone who "defines truth" when faced with contradictory viewpoints:

"A lot of it isn't textbook based, but instead articles are what you look at, and you decide. You define your own truth based on if you think the research is sound. So some people may say one thing, like, this does not cause this, and another paper will come out and say it does cause it, so whose work do you follow?" (Crystal, black woman)

The changes in PREP Scholars as they developed along the academic domain included proof to oneself and others of potential for success in graduate school classes and realization of new approaches to learning: willingness to ask more questions rather than being afraid of looking stupid; moving beyond memorizing knowledge to applying it and creating it; and learning with faculty rather than only from them. They began to think less hierarchically about the teacher-student relationship and to see learning as ongoing for everyone. As Salina, a white woman, said, "I will be working with faculty, and I won't know everything, but they won't either, so we're on the same playing field."

Development through the levels of readiness for academics was linked to several mechanisms available to the PREP Scholars beyond just attending graduate-level classes to understand expectations and approaches to teaching and learning. Many described the broader learning they took away from attending seminars along with graduate students and faculty:

"I am much more knowledgeable not only in just general scientific knowledge but more knowledgeable [from] my being exposed to the things that have been in seminars and classes. I have a better understanding of this biological system called humans. I feel like there's so many things that I've learned about, not only germ metabolism [and] pharmacology, but biochemistry, [so] that when I see something new, it's not like I'm just seeing it for the very first time. I feel I increased my knowledge base just [in] general science, like basic science. I feel I'm a lot stronger than I was when I first got here." (Hirsi, black man)

Another key activity promoting academic readiness, which crossed over to the research domain, was time afforded by PREP for reading papers from several disciplines with guided, repeated practice and feedback, for example, journal clubs and literature related to research projects:

"[I plan to keep improving myself by] reading articles and understanding figures and things like that, so that next year when I get an article, I'll be able to read it easily and understand it ... [journal club] was a new experience ... that really focused a lot on understanding the intro and the figures and all that ... we had to actually explain an article to the entire PREP Scholars so that really helped out a lot and [was] an experience I didn't have in undergrad ... I'll be able to actually use this tool to advance my future career." (Rodolfo, Latino/ black man)

"I learned more about the methodology from journal clubs, and I learned more about a wide range of biomedical and genetic research that was going on because [before] all I knew was plants." (Andrea, black/Native American woman)

In summary, this domain showed benefits of participating in "real" or "authentic" graduate student academic experiences, which increased confidence and comfort to apply for and begin a $\mathrm{PhD}$ or $\mathrm{MD} / \mathrm{PhD}$ program. While several researchers (Lopatto, 2007, 2009; Russell et al., 2007; Jones et al., 2010; Laursen et al., 2010; Thiry et al., 2011; Taraban, 2012; Graham et al., 2013) have identified benefits of undergraduate participation in "real" or "authentic" research, participants in PREP benefited from "real" experiences outside the lab to think and learn like a graduate student.

Readiness for Research. Per program expectations, PREP Scholars spent the majority of their time with a research project under the mentorship of a faculty member. The goal was to gain independence with a project, and most reported being treated 
like a graduate student researcher. As in the other domains, Scholars developed readiness for research with development at the levels of acquisition, understanding, and becoming.

At the acquisition level, 38 (80\%) described gaining technical skills, and mastering technical lab skills was particularly important for the Scholars who were new to biomedical research. Desta, a black woman, who had studied nutrition, said, "I'm good at Western blotting now. Like I was telling [my graduate school interviewers], I could do it in my sleep." Likewise, Antonio's comments reflect his mastery of techniques, but perhaps more importantly, an understanding that he has more to learn than the hands-on work of research:

\begin{abstract}
"When I first got here I didn't really know much about biomedical research just my one semester in genetics [class] lab, so at least I proved that I can handle the physical aspect of research; it's just the theory I have to work on which is arguably harder ... I know enough to survive in the lab now, and I think it's a very big achievement." (Antonio, Latino/Native American)
\end{abstract}

Beyond acquiring techniques, many PREP Scholars $(n=37$; $77 \%$ ) described an increased understanding of how experiments are designed and how to interpret results, which for many contrasted with their research experiences before PREP. In the excerpts below, Scholars describe growth in thinking and understanding about research, which contrasts to "just doing" an experiment:

"[Now I'm] making sure that I understand what I'm doing completely and not just doing the experiment just to do the experiment ... the one thing I learned is that ... doing the experiments requires an equal amount or more time thinking about the experiments." (Martin, Native American man)

“Going into PREP, I wasn't quite aware of how to set up longterm experiments. To say, A plus B plus $C$ will yield here and then you can go off in this direction or this direction. Maybe I knew about each of them individually, but how to put them all together in a way to make a story line out of your research was something that being in this lab has taught me." (Theresa, Latina)

Many Scholars ( $n=32 ; 67 \%$ ) progressed beyond this understanding of technical expertise in conducting and designing experiments and talked about the necessity of developing a researcher "mind-set," which signaled to them that they understood what is required and that they could be satisfied and successful becoming graduate students and/or scientists. Margaret recognized that she had developed "the mind-set of continuously thinking about [research]" and envisions research akin to a vocation, or for her, a hobby:

"If you're doing [research] every day ... [you develop] more of the mind-set of continuously thinking about it and less of [it] like a 9:00 to 5:00 job and of something that's more of a hobby as well as a career ... you feel the disappointments and the successes ... [and] if I entered graduate school, I would know what I was getting myself into verse [sic] if I was just coming out of college." (Margaret, Latina)

Besides "mind-set" others used the terms "lifestyle," "state of mind," "mentality," and "philosophy," which, like Margaret's comment, indicates comfort with the full immersion and commitment required for becoming a graduate student. Scholars developing this mind-set linked their progression in science with becoming a "type of person" who can be persistent through down times; comfortable with mistakes; self-motivated and driven; and willing to work hard through long hours.

Several mechanisms within the research experiences in PREP-compared with most undergraduate and summer research-facilitated rapid development along the research domain. One key was being able to devote oneself full time to research, often with one's own project:

"[When] you spend a summer somewhere, you don't really get engrafted to the research. And I did do research at my home school for a year, but I was literally only in lab two days a week. I did work hard and did produce data, but you weren't really there. So it's your first time being full-time in research, and so that's what you're doing all day and so you kind of have to get deeper into it." (Joanna, black woman)

\section{And as Paul commented,}

"I feel like now I'm much more prepared to go to a graduate program than I was beforehand. I mean every day in research you gain more experience but in the beginning I was not the best and this has been a lab I've been in for a while, but I had never done it full time before so it was like the amount of work that you can get done doing it full-time was just exponential as opposed to ... seven hours a week that's nothing ... but I feel like now I can ask questions, I can read papers, I don't need someone to hover over me. Whereas before if I didn't have [mentor's name] there, I was, like, this is not gonna get done. I feel like I can develop my own experiments." (Paul, black man)

Many Scholars talked about high expectations from mentors for independence and scientific thinking beyond what was possible in summer or even academic-year undergraduate research. In these excerpts, there is evidence that, when mentors set high expectations, the Scholars took the initiative and came up with their own ideas:

"[My mentor] is very flexible and she allows us to be flexible, and I think it's working for me. We have a meeting once a week, but she'll be in and out of her office if I need to find her. She answers email really quickly. She just gives me a bunch of idea tipping points, and then she lets me-so a couple weeks ago, she said, 'Next week tell me all the experiments you would do with this protein.' I wanted to impress her, so I found all these papers and came up with a list of experiments, and we talked about it. So I think she's trying to get me into the graduate student mind-set." (Stephanie, Latina)

"I was asking [the postdoc], 'Oh, so can I do this?' She's, like, 'You can do whatever you want. You don't have to ask me.' And then from there, I was, like, 'Okay.' That's when I came up with this laundry list of things that I could do, and our PI was thrilled and really taken aback. She's, like, 'That's a good idea."' (Leticia, black woman)

Some PIs clearly explained expectations for graduate student research that helped PREP Scholars develop readiness for research. Below, Andrea recounts her PI's explicit expectations for graduate student independence in the lab: 
"[My PI] was telling me, 'You're a graduate student now. I'm just supposed to tell you where everything is and back you on, like, certain things and help you when you need to be helped the first couple months, and then after that, you'll just gradually shift away from me,' and that's what happened. I didn't believe her. I thought I would be, like, on her back [asking her] what do I do today? And it just happened. I can't explain it ... she was right. I'm sitting right next to her desk and ... there were some days I didn't even talk to her. I'm doing all my projects myself, and the only time I talk to her is when I'm showing her a result or when I'm puzzled about something, and then that's it, I just walk off and I just do my stuff." (Andrea, black woman)

One limitation of our data is that we do not know if PREP PIs were trained to provide high (although realistic) expectations and make the graduate student researcher role explicit, but in many cases, the Scholars recounted these expectations word for word and described how the new understanding of the graduate researcher role changed their thinking and behavior in the lab.

Readiness to Present Oneself. The domain of readiness to present oneself emerged during the analysis and was not an expectation for growth mentioned by Scholars entering PREP. This domain highlights the role of external recognition and the ways it can reinforce an internal sense of one's competence. By learning and practicing communication skills, the Scholars both experienced feedback and recognition from others and came to see that the process of communicating science was integral to becoming successful graduate student researchers and scientists. Within the PREP context, Scholars received recognition from various important scientific others, for example, the graduate students, postdocs, PIs, and scientists in the PREP labs and institutions. Readiness to present oneself was a more novel result compared with the expected development along the academic and research domains. As Nathan commented, "It's not just the academic and research side that I thought was gonna be my main focus but how to convey my personality ... to others. [That] was the extra I got from the program too." These "extra" gains described by Nathan and many others resulted from multiple experiences to learn and practice communication skills, for example, presenting, writing, networking, and interviewing. As with the other two domains, we identified three levels of readiness from acquiring skills to using these skills for understanding to, finally, how experiences with science communication impact how one envisions $\mathrm{him} /$ herself becoming a graduate student and scientist.

PREP scholars $(n=32 ; 67 \%)$ acquired scientific communication skills in writing and speaking, which built confidence through practice. As Desta, a black woman, described, "We practiced in front of each other ... that was really extremely helpful, and just learning to speak in front of people and building up more confidence was really helpful." In addition, Scholars spoke of how learning and practicing communication for one purpose carried over to another. Nathan explained how gaining skills in clarity and logic while writing his graduate school essay will carry over into improved writing to convey his scientific ideas:

"We'd go through draft after draft after draft trying to really polish [my personal statement] and think clearly how to organize [it] ... I start off writing and then go sentence by sentence to see how they flow together ... that's one of the best skills I have now-being [able] to logically put words together to convey an idea." (Nathan, black man)

An important part of acquiring communication skills was learning to adapt these to multiple purposes and audiences, as Peter described:

"I was doing human research ... it was more like learning politics, as a matter of fact. I had to do a lot of meeting people, going to a lot of meetings with my mentor, doing this, doing that, getting equipment for this, you know, talking to this person. I never met this person, but I have to go talk to him. It was just a lot of networking politics. And then on top of that, I had to learn how to write grants, read them, and all kinds of stuff like that. And it really revolved around learning how to present yourself in the best possible manner." (Peter, Native American man)

Beyond acquiring communication skills, using those skills facilitated understanding science and assessing where Scholars' gaps in understanding concepts and their projects might be. Twenty-five Scholars (52\%) recognized the value of gains in communication skills to their increased scientific understanding. Using scientific language, as Lisa describes, contributed to her deeper understanding of abstract ideas:

"It's one thing to ... be able to repeat things back. But, it's completely different when you actually have to speak it, and use the language verbally ... [to] be able to answer more abstract questions." (Lisa, Latina)

Finally, PREP Scholars ( $n=28$; 58\%) realized that presenting oneself to others was integral to becoming a graduate student and working as a scientist. As in the other domains, PREP facilitated new understandings of what it meant to become a successful researcher, as revealed in the following excerpts. Becoming successful was no longer perceived as doing well in isolation but required networking and communicating to enhance and share one's thinking with others:

"It's a very big difference from undergrad because there's so much more.... not just all classes that you just pass to get a degree, you have to show work for everything you've done, and you have to show, like, your expertise in the area you're going into in order to get that PhD." (Anita, Latina)

\begin{abstract}
"Nowadays it's way more open and you have to have social networking and all these things. I kind of don't like that aspect. I feel like it's kind of businesslike, and I don't really like social networking, but that's the way the world works and how science works. But I just feel that I never understood that from my perception of-or stereotype of being a scientist that I gained as a kid-because I didn't know what that was. And I was, like, those people are weird and antisocial, and I start working in a lab I'm, like, oh, those people are normal." (Salina, white woman)
\end{abstract}

PREP Scholars described many guided opportunities to gain, practice, and improve written and oral communication skills. A key finding was the interrelationship of the various kinds of 
communication skills, such as how working on clarity of personal statements led to greater attention to detail in writing about science. These multiple opportunities involved both formal and informal instruction with some variation by program. Formal opportunities included workshops with instruction on grant writing, personal statements, and interviewing; presenting at conferences and PREP and lab meetings; leading journal clubs; and working on manuscripts. As well, there were multiple opportunities to informally interact with graduate students, mentors, faculty, and peers on campus and to network at conferences.

By presenting to others, PREP Scholars gained confidence and discovered the importance of others' recognition of them as graduate students and scientists. Thus, this domain highlights the role of external identity (Carlone and Johnson, 2007). At PREP and lab meetings and at conferences and graduate school interviews, Scholars were treated as legitimate young scientists and received feedback from others that reinforced their readiness to continue on the path to becoming researchers and scientists. Michael, a Native American man, figured out that acceptance for doctoral and scientific work involved more than acquiring a set of credentials. He observed, "It's not only the work you are doing in the lab. It's also how you present that work to other people, to the world."

\section{Outcomes after PREP: Looking at the Entry Patterns and Identity Development}

In our sample, the overall outcome of $85 \%(n=41)$ entering $\mathrm{PhD}$ or $\mathrm{MD} / \mathrm{PhD}$ programs is consistent with expectations for PREP programs. While 37 entered doctoral programs right after finishing PREP, four individuals spent time after PREP before starting the PhD. In these "gap years," two did lab work, one pursued a master's as a provisional admit to her $\mathrm{PhD}$, and another deferred admission for personal reasons. The outcomes after PREP are summarized in Table 3.

Even though individuals started PREP to achieve different goals, the proportion of Scholars entering $\mathrm{PhD}$ or $\mathrm{MD} / \mathrm{PhD}$ programs from all five patterns was $80 \%$ or higher. Progression along the three domains depended more on the starting point of each person and their choices of time and effort than the particular entry pattern. Thus, the design and implementation of PREP across the seven sites "worked" for a wide range of individuals. However, there were some notable differences between the groups, and these show the subtleties and variation in how identity develops.

Of the 22 Credential Seekers in our sample, 18 (81\%) began the $\mathrm{PhD}(16)$ or $\mathrm{MD} / \mathrm{PhD}(2)$, though their paths were not all similar. Twelve started the PhD after $1 \mathrm{yr}$ in PREP; four went on to $\mathrm{PhD}$ or $\mathrm{MD} / \mathrm{PhD}$ after 2 or $3 \mathrm{yr}$ in PREP; and one entered the $\mathrm{PhD}$ after doing an $\mathrm{NIH}$ postbaccalaureate program. Makeda described PREP as "perfect" for her goal of getting more research experience and also described how PREP met different needs for others. Her thoughts aptly describe the expectation shared by this group to improve upon a credential:

"They put a good emphasis on research here. I know some people came in with a different goal. They had research experience, but they wanted to boost their GPA and if that's your goal I think the PREP program is also very conducive for that because we do get to take classes, and we were considered graduate students so we have a transcript." (Makeda, black woman)

The various opportunities in PREP allowed the Credential Seekers some latitude in deciding how to participate based on what individuals thought graduate schools would evaluate (external recognition) and where they saw their strengths and weaknesses upon entering PREP (internal identity). The Credential Seekers looked to PREP as a place to fill gaps they perceived in their graduate school applications; thus, they benefited from guidance to reality test and recalibrate priorities, such as learning which credentials might carry more weight for the graduate admissions process and devoting appropriate time and effort to their development.

Many of the Path Builders shared experiences before PREP of having others tell them they were ready for graduate school, but this decision had to be their own, as Salina explains,

"I've heard multiple times that I could probably have gone straight into graduate school. Um, but I don't think that I was ready to go into graduate school. I think when you start graduate school, you have to go in with a particular mode of, um, philosophy and, um, confidence that you are in the right place

TABLE 3. Outcomes for PREP participants

\begin{tabular}{|c|c|c|c|}
\hline After PREP & Detailed description & Number & $\begin{array}{l}\text { Current status } \\
\text { (7 or } 8 \text { yr after start of PREP) }\end{array}$ \\
\hline $\mathrm{PhD}$ program & Directly from PREP & 34 & Of 38 who started $\mathrm{PhD}$ \\
\hline $\mathrm{PhD}$ program & $\begin{array}{l}\text { Gap years before PhD: } \\
\text { Lab work, NIH postbaccalaureate work, } \\
\text { deferred admission, provisional admit }\end{array}$ & 4 & $\begin{array}{l}\text { 5: PhD grads ( } 3 \text { in postdoc) } \\
\text { 21: persisting in PhD } \\
\text { 10: left } \mathrm{PhD} \text { ( } 4 \text { with master's) } \\
\text { 2: unknown }\end{array}$ \\
\hline $\mathrm{MD} / \mathrm{PhD}$ program & Directly from PREP & 3 & $\begin{array}{l}\text { 1: persisting in } \mathrm{MD} / \mathrm{PhD} \\
\text { 2: changed to } \mathrm{MD} \text { only }\end{array}$ \\
\hline Master's program & Directly from PREP & 4 & $\begin{array}{l}\text { 4: received master's } \\
\text { 2: currently in medical school }\end{array}$ \\
\hline Clinical program & Pharmacy and PA & 2 & 2: unknown \\
\hline Other & Unsure after PREP & $\begin{array}{r}1 \\
48\end{array}$ & 1: unknown \\
\hline
\end{tabular}


and you want to accomplish this. And the PREP program gave me the opportunity to be confident and know that this is exactly what I wanted." (Salina, white woman)

While for some groups PREP led to making their graduate school goal or dream possible, the Path Builders more often spoke of the impact of PREP as a "figuring out" process leading to a comfortable decision and an internal readiness to pursue the $\mathrm{PhD}$ or $\mathrm{MD} / \mathrm{PhD}$. Of the 14 Path Builders, 12 (86\%) started $\mathrm{PhD}$ (11) or $\mathrm{MD} / \mathrm{PhD}$ (1) programs after one or more years in PREP. Practice being a graduate student and discovering that they were similar to many of the graduate students they met during PREP were important experiences for this group.

The four PI Aspirants met their expectation to develop as competitive applicants to strong $\mathrm{PhD}$ programs. They focused their time on thinking about how others in high-caliber $\mathrm{PhD}$ programs would view them-an external identity, defined as an identity that can be recognized and accessed by others (Carlone, 2004; Malone and Barabino, 2009). All four were successful in getting into top-tier programs, and they felt confident communicating their potential as scientists in their graduate school interviews.

The individuals in the PI Aspirant group, which was the group most conscious of the salience of race to their career goals, also began to reframe how they saw themselves handling race contingencies. Consistent with other studies, high achievers who identify strongly with a field are vulnerable to racial stereotyping and conscious of race as a potential barrier or a source of motivation (Chang et al., 2011; Syed et al., 2011; Gazley et al., 2014). In their first interviews, the PI Aspirants had recounted awareness of and experiences with racial stereotyping and how they had developed a strategy to "work twice as hard" to disprove these stereotypes. By the end of PREP, the four PI Aspirants were still aware that their racial/ ethnic identities may influence how others view them, but they have gained confidence to handle this challenge. Paul hopes he will be able to focus less on race contingencies in the future:

\begin{abstract}
"I don't ever want to be caught in a situation where I don't know what I'm talking about because people will judge. I don't see minorities in science a lot, and I was judged here, so I feel like I'm a lot more prepared than I would have been had I not had the experience here at [university name], but I guess I don't intend to allow that to be the focus. I just try and be as prepared as I can be for whatever happens, and I just let it go from there." (Paul, black man)
\end{abstract}

Mario, a Latino, reflected that "science is a very white community, for sure," but added, "I don't feel [my skin color] would be much of a problem, because I talk with people here, and I know that I make a good impression on them, especially the professors." Tyrone has come to see himself as a "trailblazer" and as one of very few minorities who enter prestigious $\mathrm{PhD}$ programs:

"I'm a trailblazer. I'm willing to perhaps take falls, perhaps take hits, perhaps go through tough situations in order to improve lives and the outcomes of others after me ... to be able to change people's ideas, perspectives ... it's my calling or something and it's just my destiny. It's just what I'm supposed to do." (Tyrone, black man)
Four of the five Discipline Changers received multiple acceptances from strong graduate schools, and they started $\mathrm{PhD}$ programs directly from PREP. As Francisco, a Latino, said, "I got into several [good schools]. It ended up being pretty awesome. I didn't expect that many offers." Discipline Changers used the resources at PREP, particularly within their labs, to successfully redeploy research skills from other fields to biomedical research. They developed a clearer and more specific sense of themselves as $\mathrm{PhD}$ students with increased interest in investigating scientific questions.

The three Interest Testers recognized they were different from their peers in PREP because of their lack of undergraduate research, but by the end of PREP, all could see themselves pursuing the $\mathrm{PhD}$. Two were accepted into $\mathrm{PhD}$ programs right after PREP, and one started the PhD after 2 yr of working. Perhaps more than others in our study, the Interest Testers explicitly described a change in identity as these three short excerpts reveal: "I became a researcher" (Antonio, Latino/ Native American); "so it's kind of weird just to know that I'm actually in a category of, like, scientists" (Jasmine, black woman); and "I went from being-it was like kind of zero-to what I have now ... I'm a young scientist" (Anita, Latina). The Interest Testers focused on internal identity work as they found research to be a viable career path and developed new conceptions of themselves working in research.

Our first interviews with PREP Scholars occurred in the fall of 2009 and 2010, and with our ongoing study, we are continuing to follow participants with the exception of a few whose outcomes are not known. As shown in Table 3, of the 38 who started the $\mathrm{PhD}$, five have received their $\mathrm{PhD}$, and three of these have or will start postdoc positions. Twenty-one are still in a $\mathrm{PhD}$ program. Overall, then, 68\% (26/38) have graduated or are in a $\mathrm{PhD}$ program. Of the three who started the $\mathrm{MD} / \mathrm{PhD}$, one is persisting and two are continuing only with the MD.

While the outcome in our sample of $85 \%(n=41)$ matriculation to the $\mathrm{PhD}$ or $\mathrm{MD} / \mathrm{PhD}$ exceeded PREP expectations, seven Scholars (15\%) did not go on to $\mathrm{PhD}$ or $\mathrm{MD} / \mathrm{PhD}$ programs. The data revealed that four changed only at the pre-"becoming" levels of the domains. One described a greater "understanding" of experiments in his lab compared with his undergraduate research experiences, and three were satisfied with "acquiring" something, such as proficiency with research techniques, better problem-solving skills, and increased organizational skills. The other three perceived very little change in their development during PREP. Overall, these seven had more difficulty describing changes and development during PREP. Five of them found alignment with non biomedical research graduate programs, and only two in our sample were not successful in their application to the PhD.

Of the seven not going on to the $\mathrm{PhD}$, five are pursuing STEM careers outside of biomedical research. Three realized that their primary interest was in clinical medicine and began working toward that goal (two in medical school and one in a physician assistant program). One, who expressed a strong identity with technical problem solving and who had an undergraduate engineering degree, started in an engineering master's program. One entered a pharmacy program outside the United States. PREP played an important role in preventing these five from starting the $\mathrm{PhD}$ or $\mathrm{MD} / \mathrm{PhD}$, which they realized did not fit with their internal identities as science people 
(Carlone and Johnson, 2007). For these students, PREP offered the time and a space where they could discover they did not want to become biomedical researchers.

Only two in our sample were unhappy with their outcome after PREP; each had applied but was not accepted into a PhD program. Ayana, a black woman, could envision herself continuing with biomedical research, because she liked benchwork and desired an industry career, and she started a master's program hoping to bridge to the $\mathrm{PhD}$. The other, Jared, was the only person in the study who expressed an overall negative experience in PREP. He left without a clear plan and applied to lab technician jobs without success. In the excerpt below, we see that Jared has not developed an internal identity of himself as a scientist, despite thinking others might see this in him:

\begin{abstract}
"Is science part of my identity? You know, I think it's starting to become part of my identity. I didn't think of it as my identity before, but now that you mention it, yeah, because I mean I've done so much, considering that I recently was published. I think that kind of bolstered that identity thing, you know ... but do I see myself as a scientist? In other people's eyes, yes. If I were to rephrase the question, do I see myself through my eyes as a scientist? No. Not at all. I don't know." (Jared, black man)
\end{abstract}

Both shared some difficulties with their PIs: Ayana felt her PI "wasn't pleased with [her] presence [in the lab]," and Jared didn't feel challenged or that his PI was "interested in his development." So it is possible that a poor mentor performance or mentor-mentee match contributed to their disappointing outcome. However, the other five had positive and strong mentoring relationships. Thus, in this subset of PREP scholars, at most, two had potential mismatches with mentors that may have contributed to their lack of progression to the $\mathrm{PhD}$.

A notable result is that 10 of the $37(27 \%)$ have left their $\mathrm{PhD}$ programs, with four of them receiving master's degrees. While a closer analysis of their decisions to leave the $\mathrm{PhD}$ is beyond the scope of this paper, we note that they represent three patterns: five Credential Seekers, four Path Builders, and one Interest Tester. The absence of PI Aspirants and Discipline Changers leaving doctoral programs may be linked to their starting PREP with a stronger identity of succeeding as researchers and graduate students. The PI Aspirants looked beyond the $\mathrm{PhD}$ to see themselves developing independent research agendas as biomedical faculty; and the Discipline Changers came to PREP with positive images of themselves as skilled researchers (though developed in nonbiomedical fields) and future faculty pursuing nascent research questions. Further research is needed to determine whether these aspects of identity are associated with longer-term trajectories of success in the $\mathrm{PhD}$ and subsequent academic careers.

\section{DISCUSSION}

The results from this second chapter in our longitudinal study of PREP Scholars revealed how Scholars interacted with program elements, research mentors, and program leaders to accomplish what they sought from PREP and to develop in ways they had not anticipated. The results also revealed insights and mechanisms that help explain the positive outcomes across PREP reported by Hall and colleagues in 2015. The three domains of academics, research, and presentation reflect how aspiring biomedical doctoral students think about their preparation and highlights the importance that the design of a PREP experience be attuned to individual needs rather than a onesize-fits-all expectation. Not only do PREP Scholars start with different goals and purposes (Gazley et al., 2014), they also enter at highly variable positions along the three domains. The outcome that a high and similar rate of progression from PREP to $\mathrm{PhD}$ and $\mathrm{MD} / \mathrm{PhD}$ programs occurred across various starting points leads to the conclusion that the programs sampled in this study effectively enabled growth and development for the wide array of Scholar starting points.

We use the term "mechanism" in talking about the impacts of PREP to link the nature of various activities and design elements of PREP to the change or growth it stimulates. For example, readiness to present oneself occurs as a result of multiple, guided opportunities to talk about science with peer and expert feedback. Independence in research occurs through a substantive yearlong project with guided expectations to become more independent. Although situated within PREP, many of the approaches described above could be applied in other research training situations with the likelihood of similar impacts with sufficient time and effort and developmentally appropriate expectations.

The relationship between identity development and professional goal setting continues to be a lively area of scholarship (see, e.g., Hernandez et al., 2013). Across the three domains, we found Scholars were able to try on and practice new identities that they aligned with becoming a graduate student and being accepted by others in this role. Some could envision identities of practicing scientists, but it does not appear necessary to have a long-term professional goal to achieve commitment to and acceptance into a PhD program as a first step. In PREP, Scholars saw and experienced what being a graduate student entails and calibrated their expectations and aspirations with graduate students just ahead of them.

Being treated like a graduate student in a graduate school environment allowed Scholars to experiment with feeling like a graduate student. This, in turn, provided data to answer their questions: Can I be a successful graduate student and do I want to become that kind of science person? As we have shown, those who felt they needed academic prerequisites also discovered new ways they would be expected to perform in graduate classes and practiced applying and critiquing knowledge beyond just memorizing facts. With all Scholars engaged in mentored research, our results showed that Scholars progressed along the research domain when mentors made it clear that graduate students were expected to troubleshoot experiments, consult previous literature, and bring their ideas to projects. Keys to their progression in the academic and research domains were the opportunities to interact in authentic classroom and research environments at a point in time when they could compare their new experiences with what had been expected of them as undergraduates. A key implication for development along these two domains is to provide authentic experiences combined with explicit guidance for growth beyond the acquiring of skills.

A strong finding was the role of readiness to present oneself and how this domain facilitated PREP Scholars feeling ready to present their internal identities as a graduate students to others. This domain draws on two methods of cognitive apprenticeships 
found to be important for becoming a researcher: articulating scientific knowledge and reflecting on that knowledge compared with others (Feldman et al., 2013). However, the most powerful feature of this domain comes from how speaking and writing about doing science engaged the Scholars in identity work around being and becoming science $\mathrm{PhD}$ students. This theme emerged over time, especially as Scholars got closer to interviewing for graduate school and anticipating that interviewers would evaluate them not only on their credentials but on how they presented themselves as the "type of person" who could be successful at a given school. This focus on how others will perceive them highlights that identity development occurs in an iterative cycle of internal views of the self that are strengthened though external recognition by important others (Carlone and Johnson, 2007). This growth in confidence to present oneself draws on increased competence with the practices of doing research and functioning as a graduate student/young scientist; it does not appear just out of introspection. In their quantitative study, Cameron and colleagues (2015) found that acquisition and thoughts about science communication are linked to intention to stay in careers for doctoral and postdoctoral trainees. From our study, we saw how science communication and practice also facilitated the intention to apply for and enroll in a $\mathrm{PhD}$ or $\mathrm{MD} / \mathrm{PhD}$ program and provided a means by which these PREP participants could demonstrate their potential to themselves and others. A second key implication for program practitioners and mentors is to incorporate direct instruction in reading, writing, and speaking about science; guided practice in front of varied audiences; and an explicit rationale about the role of communication skills for progression as a graduate student and scientist.

There are some limitations with our study. First, although the sample size is large for a multiyear, longitudinal, in-depth qualitative study, it is too small to make robust comparisons between subgroups based on gender, race, or ethnicity. Comparing students between these variables did not reveal any strong or consistent differences, and differences within any subgroup were as prevalent as differences between them. Likewise, there was not a sufficient number of Scholars from each PREP site to reveal any differences between the sites. One of the goals of the larger NLSYLS parent study is to examine differences in career progressions within demographic subgroups as well as to investigate longer-term impact on graduate school persistence and career choice related to PREP participation.

As noted, not all PREP Scholars matriculated to $\mathrm{PhD}$ or MD/ $\mathrm{PhD}$ programs. We concluded that almost none of them would be classified as program failures but rather appropriate outcomes for individuals entering PREP to determine whether the $\mathrm{PhD}$ was right for them. A question to be addressed in future studies is the degree to which those who enter the $\mathrm{PhD}$ or $\mathrm{MD} /$ $\mathrm{PhD}$ from PREP complete the degree and persist with a research career. Through the time of writing, 12 of the Scholars who started the $\mathrm{PhD}$ or $\mathrm{MD} / \mathrm{PhD}$ have left either the $\mathrm{PhD}$ or the $\mathrm{PhD}$ portion of the $\mathrm{MD} / \mathrm{PhD}$. When the Scholars in this study have either completed or left the $\mathrm{PhD}$, it will be possible to compare and interpret reasons for these decisions.

By being chosen for PREP based on their potential to succeed in doctoral programs and through engagement with mentors who set high standards for performance, Scholars were treated as legitimate members of several communities: among graduate students, with colleagues in their labs and within the larger community of scientists. Recognition as a legitimate member of a learning community or community of practice allows new members to access key identity development resources within the context, such as insider information (Wenger, 1998). This conferred legitimacy via recognition and may be especially important for URM scientists, as they frequently face barriers to being seen as scientists. We posit that, by feeling accepted and valued in these communities, PREP Scholars will have a jump start as they begin graduate school and join new learning communities.

The time between undergraduate and graduate years has not been systematically explored, and this time is a critical junction for any efforts to increase diversity in STEM. These results clarify why programs work-through strategic cultivation within identity resource-rich environments of internal and external identities consonant with successful graduate students-but also how programs accomplish these goals. Individual faculty and graduate schools could design postbaccalaureate research experiences to foster development along the three domains using the mechanisms we identify. With NIH diversity supplements or funding of short-term research assistantships on grants, it would not be too difficult to replicate many of the opportunities that PREP provides. The domains and mechanisms for development suggest fruitful lines of inquiry for similar processes occurring during the undergraduate years and especially for participants in structured programs like the NIHfunded interventions of Maximizing Access to Research Careers (MARC), Research Initiative for Scientific Enhancement (RISE), and Initiative for Maximizing Student Development (IMSD) (for details of these programs, see National Institute of General Medical Sciences, 2015), and similar initiatives. Program leaders can use these results to assess their programs, train program personnel, and advise their participants in ways that will support their progression to satisfying STEM educational and career goals.

\section{ACKNOWLEDGMENTS}

We thank Jill Keller and Patricia B. Campbell for their contributions to this study and Bryan Breau and Nicole Langford for administrative support. This work is supported by NIH grants (R01GM085385, R01GM085385S1-ARRA, andR01NR011987).

\section{REFERENCES}

Bourdieu P (1984). Distinction: A Social Critique of the Judgement of Taste Cambridge, MA: Harvard University Press

Bourdieu P (1986). The forms of capital (R. Nice, Trans.). In: Handbook of Theory and Research for the Sociology of Education, ed. J. Richardson New York: Greenwood, 241-258.

Bourdieu P, Passeron JC (1977). Reproduction in Education, Society and Culture, London: Sage.

Cameron C, Lee HY, Anderson C, Byars-Winston A, Baldwin CD, Chang S (2015). The role of scientific communication skills in trainees' intention to pursue biomedical research careers: a social cognitive analysis. CBE Life Sci Educ 14, ar46.

Carlone HB (2004). The cultural production of science in reform-based physics: girls' access, participation, and resistance. J Res Sci Teach 41, 392-414.

Carlone HB, Johnson A (2007). Understanding the science experiences of successful women of color: science identity as an analytic lens. J Res Sci Teach 44, 1187-1218. 
Chang MJ, Eagan MK, Lin MH, Hurtado S (2011). Considering the impact of racial stigmas and science identity: persistence among biomedical and behavioral science aspirants. J High Educ 82, 564-596.

Feldman A, Divoll KA, Rogan-Klyve A (2013). Becoming researchers: the participation of undergraduate and graduate students in scientific research groups. Sci Educ 97, 218-234.

Gazley JL, Remich R, Naffziger-Hirsch ME, Keller J, Campbell PB, McGee R (2014). Beyond preparation: identity, cultural capital, and readiness for graduate school in the biomedical sciences. J Res Sci Teach 51, $1021-$ 1048.

Graham MJ, Frederick J, Byars-Winston A, Hunter A-B, Handelsman J (2013). Increasing persistence of college students in STEM. Science 341, 14551456.

Hall A, Mann J, Bender M (2015). Analysis of Scholar Outcomes for the NIGMS Postbaccalaureate Research Education Program. www.nigms.nih.gov/ News/reports/Documents/PREP-outcomes-report.pdf (accessed 11 December 2015).

Hernandez PR, Schultz PW, Estrada M, Woodcock A, Chance RC (2013) Sustaining optimal motivation: a longitudinal analysis of interventions to broaden participation of underrepresented students in STEM. J Educ Psychol 105, 89-107.

Holland D, Lachicotte W, Skinner D, Cain C (1998). Identity and Agency in Cultural Worlds, Cambridge, MA: Harvard University Press.

Jones MT, Barlow AEL, Villarejo M (2010). Importance of undergraduate research for minority persistence and achievement in biology. $\mathrm{J}$ High Educ 81, 83-115.

Laursen S, Hunter A, Seymour E, Thiry H, Melton G (2010). Undergraduate Research in the Sciences: Engaging Students in Real Science, San Francisco, CA: Wiley.

Lopatto D (2007). Undergraduate research experiences support science career decisions and active learning. CBE Life Sci Educ 6, 297-306.

Lopatto D (2009). Science in Solution: The Impact of Undergraduate Research on Student Learning, Tucson, AZ: Research Corporation for Science Advancement.

Malone KR, Barabino G (2009). Narrations of race in STEM research settings: identity formation and its discontents. Sci Educ 93, 485-510.

National Institute of General Medical Sciences (2015). Programs by Award Types. www.nigms.nih.gov/Training/Pages/AwardType.aspx (accessed 13 January 2015).
National Institutes of Health (NIH) (2012). Biomedical Research Workforce Working Group Report. http://biomedicalresearchworkforce.nih.gov/ docs/Biomedical_research_wgreport.pdf (accessed 19 November 2015).

NIH (2014). Postbaccalaureate Research Education Program (PREP) (R25). http://grants.nih.gov/grants/guide/pa-files/PAR-14-076.html (accessed 5 January 2016)

National Science Foundation/National Center for Science and Engineering Statistics (NSF/NCSES) (2013). Women, Minorities, and Persons with Disabilities in Science and Engineering: 2013. www.nsf.gov/statistics/ infbrief/nsf13311 (accessed 10 January 2016).

NSF/NCSES (2015). Women, Minorities, and Persons with Disabilities in Science and Engineering: 2015. www.nsf.gov/statistics/wmpd (accessed 5 January 2016).

Ovink SM, Veazey BD (2011). More than "getting us through": a case study in cultural capital enrichment of underrepresented minority undergraduates. Res High Educ 52, 370-394.

QSR International (2010). NVivo Qualitative Data Analysis Software, version 9. www.qsrinternational.com.

Russell SH, Hancock MP, McCullough J (2007). Benefits of undergraduate research experiences. Science 316, 548-549.

Steele CM (1997). A threat in the air: how stereotypes shape intellectual identity and performance. Am Psychol 52, 613-629.

Steele CM, Aronson JA (1995). Stereotype threat and the intellectual test performance of African Americans. J Pers Soc Psychol 69, 797-811.

Syed M, Azmitia M, Cooper CR (2011). Identity and academic success among underrepresented ethnic minorities: an interdisciplinary review and integration. J Soc Issues 67, 442-468.

Taraban R (2012). What is undergraduate research and why should we support it? In: Creating Effective Undergraduate Research Programs in Science: The Transformation from Student to Scientist, ed. R Taraban and RL Blanton, New York: Teachers College Press, 3-10.

Thiry H, Laursen SL, Hunter A-B (2011). What experiences help students become scientists? A comparative study of research and other sources of personal and professional gains for STEM undergraduates. J High Educ 82, 357-388.

Villerejo A, Barlow AEL, Kogan D, Veazey BD, Sweeney JK (2008). Encouraging undergraduates to choose science careers: career paths survey results. CBE Life Sci Educ 7, 394-409.

Wenger E (1998). Communities of Practice: Learning, Meaning and Identity, New York: Cambridge University Press. 